\title{
Invited commentary on: Psychiatry and the death penalty ${ }^{\dagger}$
}

\author{
Peter Hodgkinson
}

The dilemma that Dr Ferris refers to is one that I doubt will be resolved despite the American Psychiatric Association's (APA) long awaited response to the guidelines defining and prohibiting participation as proposed by the American Medical Association (AMA). The fact that it has taken nearly three years for them to respond leaves one wondering whether the APA consider this a priority. The new guidelines, which have tidied up some of the terminology, remain too loose and equivocal and offer no succour to those in the profession who might want to exercise some moral authority within their respective state professional bodies. The AMA should follow the lead of the World Association, and indeed that of the British Medical Association, in making explicit their opposition to any participation by health professionals in the capital process - they should be setting and expecting a moral standard more in keeping with their professional oath.

Failure to be this explicit has the effect of giving a green light to those practitioners who support the death penalty, thus enabling them to be employed to the advantage of the prosecution at trial and the prison authorities, State Attorneys General and the Governor during the execution phase. In those situations such practitioners become as 'death qualified' as are jurors in capital cases. The 'death qualified' juries that result do so regardless of the US Supreme Court decisions forbidding the selection of juries on the grounds of their support for the death penalty.

An equally important task for the APA would be to help disentangle the politics of penality from the diagnostic process. The history of capital litigation is littered with examples of what I consider to be punitive and discriminatory diagnostic practice. Perhaps I am being a little harsh, for as recently as July 1995 the APA did

'See pp. 746-748. eventually expel the forensic psychiatrist $\mathrm{Dr}$ Grigson, sometimes known as Dr Death, a title awarded in recognition of his expert testimony on behalf of the prosecution in over 144 capital trials. His repertoire of diagnostic accomplishments includes giving his opinion to the prosecution based on hypotheticals, on transcripts of the trial and occasionally after having met the defendant. The US Supreme Court has affirmed the legality of such expert testimony based on hypotheticals. So confident was he of his capacity to identify future lethal dangerousness, on the basis of this diagnostic process, that he continues to claim that he was correct in the case of a condemned man released from death row even after his conviction was overturned.

It will come as no surprise to most of us that politics influences decision-making processes in the legal and penal systems. The relationship between the two in the USA is transparent and so powerful that its influence extends to the diagnoses reached by psychiatrists. Miller \& Radelet in their book Executing the Mentally II recount what can only be called a number of horror stories describing disturbed and disordered behaviours that were deemed not to constitute mental illness by courts, at all levels, and by psychiatrists retained by the prosecution and employed by the Department of Corrections. Even allowing for the healthy ebb and flow of differential diagnosis in the behavioural sciences the illustrations they provide in their book would not be judged within the normal range by informed observers.

Thirty-eight states, the Federal Government and the US Military have the death penalty. Physicians are in attendance at all executions irrespective of mode of execution. The long awaited guidelines have done little to clarify the ethically appropriate participation of mental health professionals. The separation of the roles of evaluation and treatment are helpful to the theory but perhaps not to the practice of psychiatry in a penal setting. It is perfectly possible, in fact likely, that the physician that 
treats (not to restore competence for execution) will belong to the same community that evaluates competence for execution - psychiatrists for the defence and for the prosecution.

It matters not what guidelines the AMA draft, without its unequivocal condemnation some psychiatrists will continue to actively and enthusiastically support the machinery of death in the USA. The politics of penality will ensure that.

\section{Reference}

MILLER, K. \& RADELET, M. (1993) Executing the Mentally Ill The Criminal Justice System and the Case of Alvin Ford. Thousand Oaks. CA: Sage Press.

Peter Hodgkinson, Senior Lecturer in Law, Director of the Centre for Capital Punishment Studies, University of Westminster, 4 Red Lion Square, London WCIR 4SR

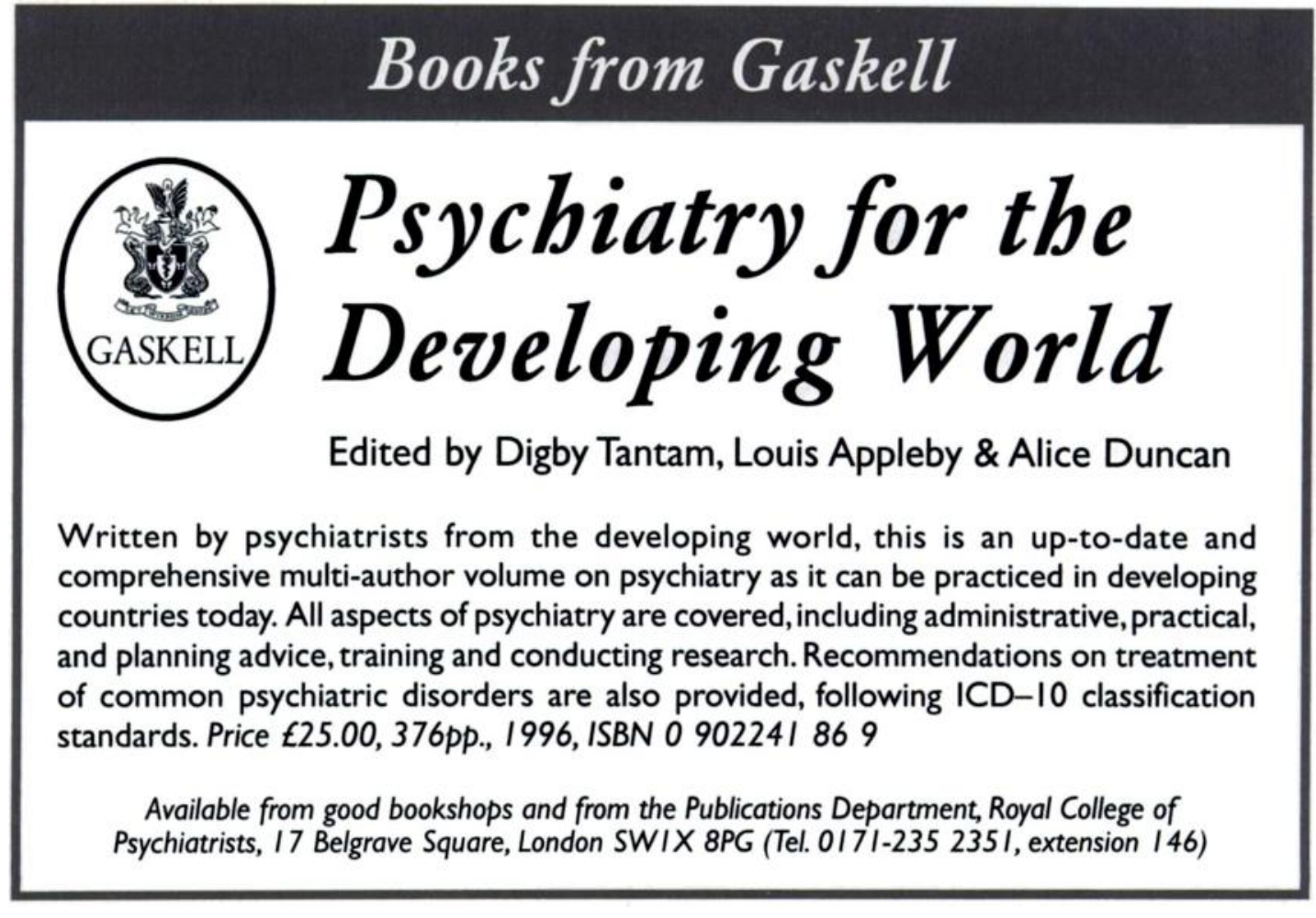

